\title{
MODEL PENDEKATAN PERJUANGAN EMANSIPASI R.A.KARTINI DARI PERSPEKTIF PERJUANGAN KESETARAAN GENDER DEWASA INI (SEBUAH KAJIAN KEPUSTAKAAN)
}

\author{
Ida Ayu Putu Mahyuni \\ Program Studi Sejarah Fakultas Ilmu Budaya Unud \\ sonik.hungry@gmail.com
}

\begin{abstract}
Raden Ajeng (R.A.) Kartini has been known as an Indonesian women's emancipation fighter. In addition, R.A.Kartini is also known as the pioneer of the Indonesian nationalist movement, hence the state has appointed him a national independence hero (Moedjanto, 1983: IV). R.A.Kartini emancipation struggle is not done in a physical struggle, but done through the struggle of his thoughts or ideas. This paper reveals the emancipation struggle approach model R.A. Kartini from the perspective of the struggle for gender equality today (a literary review). To understand this problem, gender analysis is used as an analytical tool to understand the social realities of gender-differentiated relations between men and women. The concept of emancipation is not much different from the concept of struggle of gender equality known today, these two concepts aims to fight for the rights of women with men to be equal and equal in accordance with the context of the ability of each individual. Gender itself is a concept that refers to men and women who are distinguished not biologically or naturally but are distinguished on the basis of social and cultural constructs. Thus, both men's and women's societies can create, socialize, reinforce gender-based differences, so long as gender differences do not create injustice between men and women no matter the need to be sued, but the issue is when gender differences are constructed social and cultural causes of gender injustice that harm both men, especially for women (Fakih, 1999: 12). In connection With this there are several issues that need to be studied, among others: 1. How to model the approach to emancipation struggle R.A.Kartini in advancing the education of women? 2. How is the approach model of R.A.Kartini emancipation struggle fostering equality in family and marriage? 3. How does the emancipation struggle approach model of R.A.Kartini foster equality in improving the welfare of the people? All these issues will be examined from the perspective of today's gender equality struggle.
\end{abstract}

Key word: Emansipasi, kesetaraan gender dan gender

\section{LATAR BELAKANG DAN MASALAH}

Menurut Ratna Megawangi (1999), pendekatan Kartini untuk kebebasan perempuan bukan dengan model konflik yang berasumsi bahwa pola relasi sosial selalu berdasarkan konflik penguasa (laki-laki) dan subordinat perempuan. Namun lebih berdasarkan pada model fungsional, dimana hubungan laki-laki dan perempuan merupakan kesatuan yang saling melengkapi. Untuk dapat memahami tentang model pendekatan Kartini dalam perjuangan emansipasinya, maka sumber yang paling tepat adalah surat-surat Kartini.

Perjuangan untuk meningkatkan posisi perempuan agar setara dengan laki-laki sesungguhnya sudah tertanam dalam pemikiran seorang putri Indonesia yang ketika itu masih belia. R.A. Kartini yang lahir dan dibesarkan di lingkungan masyarakat yang masih sangat 
teguh memegang tradisi dan adat istiadat. Selain itu Kartini juga hidup dalam masa kekuasaan pemerintah kolonial Belanda. Kartini kecil menghabiskan waktunya terutama di lingkungan keluarga bangsawan yang cukup modern ukuran jamannya. Ayahnya adalah seorang bupati yang berpikiran maju, namun juga taat pada tradisi dan adat istiadat yang berlaku ketika itu. Karena itu pandangan dan perjuangan emansipasi R.A.Kartini tidak terlepas dari 1) keadaan tanah air kita sebelum dan setelah penjajahan Belanda, (2) adat feodal yang masih sangat kuat yang menjadi hambatan besar masuknya gagasa-gagasan baru dari Barat ( Soeroto, $1983: 1$ ).

Gagasan pemikiran Kartini juga tidak dapat dilepaskan dari beberapa hal, antara lain : 1 . pengaruh dari keluarganya, terutama kakek dan ayah Kartini yang memiliki pemikiran yang sangat maju pada jamannya. Kakeknya, Pangeran Ario Tjondronegoro, Ia adalah Bupati pertama yang mendidik anak-anaknya, laki-laki dan perempuan dengan pendidikan ala Barat (Rosyadi, 2010 : 14). 2) selain itu pada tahun 1902 di seluruh pulau Jawa hanya empat orang Bupati yang pandai menulis dan bercakap-cakap dalam bahasa Belanda, diantaranya ayah Kartini yaitu R.M.Adipati Ario Sosroningrat (Pane, 2000 : 3). Bahkan Ia mengizinkan anak perempuannya masuk sekolah dasar Belanda. Tindakan ini cukup berani untuk jamannya (Soebadio dan Saparinah Sadli, 1990 : 22) 3)Bahan Bacaan seperti majalah, artikel, buku, dan artikel yang ada menjadi pengetahuan yang sangat berharga bagi Kartini untuk menambah pengetahuan. Dari bahan bacaan yang sangat beragam itu Kartini dapat mengetahui tentang pergerakan perempuan Eropa. Sejak kecil Kartini tergolong gemar membaca. Berbagai bahan bacaan dibacanya, kecuali bahan bacaan yang dapat menyinggung perasaan dan kasar disingkirkan atau dibuang (Soeroto, 1983 :76).

Kartini memang mengagumi kebudayaan Barat terutama dalam hal ilmu pengetahuannya, namun juga tetap selektif dan kritis. Ia hanya mau mengambil yang baik saja yang dapat mempertinggi peradaban bangsanya sendiri. Sebagian pemikiran Kartini untuk menilai peradaban Barat ketika itu dapat dilihat pada salah satu bagian suratnya kepada Ny.Abendanon yang diterjemahkan oleh Sitisoemandari Soeroto (1983) berikut :

“...tatkala kami dengan sungguh-sungguh mengira bahwa 'masyarakat Eropa adalah satu-satunya yang paling baik, tak ada taranya'. Maafkanlah kami, tetapi apakah Ibu sendiri menganggap masyarakat Eropa itu sempurna ? Wahai kami mengakui dengan rasa sangat terima kasih adanya banyak, sangat banyak yang bagus dalam dunia Ibu. Tetapi dapatkah Bunda menyangkal bahwa di samping hal-hal yang indah dan mulia dalam masyarakat Bunda terdapat banyak juga hal-hal yang sama sekali tidak patut dinamakan 'peradaban'...."

Dari berbagai bahan bacaan, Kartini dapat mengetahui tentang gerakan sosialis dan perjuangan hak perempuan. Bahkan sejak berumur 10 atau 11 tahun, Kartini sudah membaca tentang perjuangan perempuan, berbangsa India, Pandita Ramabai yang saat itu ramai diperbincangkan di surat kabar (Soebadio dan Saparinah Sadli, 1990 : 26). Hubungan melalui surat-menyurat, baik dengan Nyonya dan Tuan Abendanon dan sahabatsahabat lainnya, selain dapat mengungkapkan keresahan hatinya dan juga cita-citanya untuk memajukan pendidikan bangsanya terutama kaum perempuan. Dari sejumlah surat-surat Kartini inilah dapat diketahui betapa mulia cita-citanya yang hingga kini masih dapat dijadikan sebagai inspirasi baik bagi kaum perempuan maupun kaum laki-laki dalam mewujudkan kesetaraan gender.

Dari latar belakang permasalahan tersebut, muncul pertanyaan : Bagaimana model pendekatan perjuangan emansipasi R.A.Kartini, baik dalam memajukan pendidikan perempuan maupun bangsanya ?, Bagaimana model pendekatan perjuangan emansipasi R.A.Kartini dalam membina kesetaraan dalam keluarga dan perkawinan ? dan Bagaimana model pendekatan perjuangan emansipasi R.A.Kartini dalam meningkatkan kesejahteraan rakyat kecil ? Semua permasalahan ini dikaji dari perspektif kesetaraan gender dewasa ini. 


\section{Model Pendekatan Perjuangan Emansipasi}

R.A.Kartini dalam Pendidikan dan Membina Persatuan Bangsa.

Pemikiran Kartini yang kuat untuk memajukan pendidikan bagi kaum perempuan Jawa tercermin dalam beberapa surat-suratnya. Surat Kartini (31-1-1901) kepada Ny.R.M.Abendanon-Mandri, seperti yang diterjemahkan oleh Sulastin Sutrisno (2000 : 74) berikut :

“...saya lama dan banyak sekali memikirkan tentang pendidikan...Saya pandang pendidikan itu suatu tugas yang luhur dan suci sehingga...Bagi saya pendidikan itu pembentukan semangat dan jiwa...."

Dalam surat yang sama Kartini mendengar berita pengajaran untuk anak-anak perempuan Bumiputra, sebagai berikut :

“...Aduhai dengan hangat saya perkuat pikiran saya, yang dengan sangat jelas dibaca dalam surat edaran mengenai pengajaran untuk anak-anak perempuan Bumiputra : perempuan sebagai pendukung peradaban !...Perempuanlah yang paling banyak dapat membantu meningkatkan kadar kesusilaan umat manusia...Dari perempuan manusia menerima pendidikannya yang pertamatama, di pangkuannya anak belajar merasa, berpikir, berbicara...Dan bagaimana ibuibu Bumiputra itu dapat mendidik anakanak mereka kalau mereka sendiri tidak terdidik....”

Dari pemikiran Kartini yang dituangkan ke dalam suratnya menunjukkan betapa majunya pemikiran Kartini. Anak yang tergolong masih berusia belia pada saat itu, sudah dapat memikirkan kepentingan pendidikan yang harus diberikan terutama kepada perempuan.

Keinginan untuk memperjuangkan pendidikan kaum perempuan Bumiputra juga mendapat inspirasi dari perjuangan perempuan dari negara lain. Jika bukan karena Kartini sangat gemar membaca berbagai macam bacaan yang berguna menambah pengetahuan yang menurutnya sangatlah penting dan berguna bagi kemajuan bangsanya terutama bagi kemajuan kaum perempuan yang menurut pengamatannya pendidikan perempuan pribumi masih sangat terbelakang, Ia menginginkan agar kaum perempuan pun harus mendapatkan pendidikan formal. Dari bagian suratnya yang diterjemahkan oleh Sitisoemandari Soeroto (1983 : 45), menunjukkan betapa tertariknya Ia dengan perjuangan yang dilakukan oleh Pundita Ramabai yang menurut pengamatannya bukan berasal dari negara Barat, bukan bangsa berkulit putih, namun orang berkulit sawo matang sama dengan dirinya. Sebagian petikan suratnya, sebagai berikut :

“...sudah beberapa kali kami mendengar tentang pejoang wanita India yang berani itu. Saya masih sekolah tatkala saya untuk pertama kali mendengar tentang dia. O, saya masih ingat benar; waktu itu saya masih sangat muda, baru 10 atau 11 tahun, hati saya menyala-nyala tatkala saya membaca tentang dia di surat kabar. Saya sampai menggigil karena emosi: Jadi tidak hanya wanita kulit putih yang dapat mencapai kehidupan bebas!..wanita berkulit sawo matang juga dapat membebaskan diri dan hidup berdiri sendiri...Apa saja yang yang tidak dapat dicapai oleh satu contoh yang baik dan berani...."

Melalui surat-surat Kartini diketahui bahwa perjuangan emansipasi yang dilakukan bukan semata-mata untuk kemajuan perempuan Jawa, namun juga untuk kemajuan perempuan bahkan bangsanya Hindia dulu atau sekarang Indonesia baik laki-laki maupun perempuan. Sehingga Kartini juga dikenal sebagai perintis pergerakan nasional Indonesia. Kartini juga sangat bangga memiliki bangsa yang cerdas, seperti yang dikenal bernama Abdul Rivai seorang berasal dari Minang yang pertama menjadi dokter lulusan Stovia. Dalam suratnya kepada Nyonya AbendanonMandri, Kartini menulis berikut: 
“...Oh, alangkah senang hati kami, bila dapat berhubungan dengan anak-anak muda bangsa kami yang terpelajar dan suka akan kemajuan, seperti Abdul Rivai dan lainlain...." (Moedjanto, 1983 : IV).

Tentang pendidikan, Ki Soeratman (1990 : 31) berpendapat, bila disimak kembali bukankah gagasan pemikiran R.A. Kartini menggunakan pendidikan sebagai dasar dalam perjuangan memajukan bangsa (laki-laki maupun perempuan) pada saat pergerakan kebangsaan belum lahir dan politik praktis juga belum berkembang. Berikutnya pergerakan nasional pertama di Indonesia adalah Budi Utomo dengan salah satu programnya adalah pendidikan bagi bangsa Indonesia untuk mendapatkan pengakuan sebagai bangsa yang sederajat dengan bangsa yang menjajahnya. Demikian halnya dengan pembukaan UUD 1945 bahwa melalui pendidikan sama artinya dengan mencerdaskan kehidupan bangsa.

Melalui suratnya pula, dapat dipahami bahwa gagasan-gagasan pemikirannya untuk kemajuan bangsanya mendapat respon positif dari pemuda pelajar bangsanya. Dari suratnya itu menunjukkan bahwa model pendekatan perjuangan emansipasi Kartini jelas bukan dilakukan dengan model konflik antara penguasa (laki-laki) dan subordinat perempuan melainkan dengan model fungsional bahwa laki-laki dan perempuan merupakan kesatuan yang saling melengkapi dan saling mendukung satu dengan yang lain untuk kemajuan bersama. Seperti surat Kartini diterjemahkan oleh Sitisoemandari Soeroto, 1983 : 335, berikut

“...Kami telah mendapat banyak pengikut. Angkatan muda kita telah mendukung sepenuhnya. 'Jong Java' akan membangun persatuan, dan sudah tentu kami menggabung...Mereka menamakan saya 'Ayunda'. Saya menjadi kakak mereka, pada siapa mereka setiap waktu dapat datang kalau mereka memerlukan bantuan atau pelipur hati...Ia sealiran dengan kami dan bercita-cita untuk bekerja bagi rakyatnya...."
Model pendekatan perjuangan Kartini terhadap bangsanya dapat dipahami kalau Kartini rela menyerahkan beasiswa yang diterimanya kepada Salim. Salim seperti yang dikatakan dalam suratnya kepada Ny. Abendanon-Mandri, berasal dari Riau, Sumatra (Moedjanto, 1983 : IV). Berarti Salim jelas bukan berasal dari Jawa atau orang Jawa dimana Kartini hidup dan dibesarkan. Inilah salah satu model pendekatan perjuangan emansipasi R.A.Kartini berkaitan dengan kemajuan pendidikan bangsa. Selain itu betapa modern gagasan Kartini untuk membangun persatuan bangsa, laki-laki dan Perempuan. Dalam satu suratnya kepada Ny.Abendanon, 30 September 1900, sebagai berikut:

“...Kaum muda, wanita dan pria, seharusnya saling berhubungan. Mereka seorangseorang dapat berbuat sesuatu untuk mengangkat martabat bangsa kita. Tetapi jika semua kita bersatu, menyatupadukan kekuatan kita dan bekerja sama,..hasil pekerjaan kita akan jauh lebih besar...." (Soeroto, $1993:$ 334).

Gagasan R.A.Kartini untuk kesetaraan antara laki-laki perempuan dapat dipahami dari pandangannya, bahwa perjuangannya bukan bermaksud melawan laki-laki, melainkan adat kolot yang menjadi sumber ketidaksetaraan antara laki-laki dan perempuan itulah yang perlu dilawan. Gagasan ini tetntu sejalan dengan perjuangan kesetaraan gender yang kita kenal dewasa ini. Menurut Kartini memang ada juga laki-laki dari seorang pejabat pribumi yang berpangkat tinggi mengatakan, bahwa perempuan yang beradab dan terpelajar menjadi penolong dan pembantu berharga bagi laki-laki (Rosyadi, 2010 : 63)

\section{Model Pendekatan dalam Membina}

\section{Kesetaraan dalam Keluarga dan Perkawinan}

Model pendekatan yang digunakan untuk memperbaiki kedudukan perempuan dalam keluarga dan perkawinan, Kartini banyak belajar dari lingkungan dimana Ia hidup dan dibesarkan. 
Kartini telah melihat dan merasakan masa dimana Ia dan saudara perempuan selepas sekolah pada umur belasan tahun harus memasuki masa pingit, untuk kemudian menunggu lamaran dari laki-laki yang akan menikahinya. Walaupun Ia sesungguhnya sangat anti poligami, namun akhirnya Ia sendiri dilamar dan dinikahi oleh lakilaki yang sudah memiliki istri. tradisi dan adat yang sangat kuat pengaruhnya sehingga Kartini tidak berdaya untuk melawannya.

Berkaitan dengan hal perkawinan, perjuangan Kartini bukan dilakukan secara membabi buta, Dia masih menghormati posisi ayahnya agar tidak menanggung malu karena putrinya tidak mengindahkan adat yang berlaku. Walaupun sesungguhnya ayah Kartini sangat mengerti yang diinginkan anak gadisnya. Akan tetapi karena adat, ayahnya pun tidak bisa banyak berbuat untuk anaknya. Masih beruntung anakanak perempuannya diijinkan untuk bersekolah walaupun hanya setingkat sekolah dasar Belanda. Namun ayah Kartini belum sanggup menghindari adat yang berlaku pada saat itu, anak gadisnya akan dikawinkan dengan laki-laki pilihan ayahnya (Soebadio dan Saparinah Sadli, 1990 : 37).

Keadaan menyebabkan tidak banyak dapat dilakukan oleh Kartini untuk cita-citanya memperoleh pendidikan yang lebih tinggi. Kartini kembali dihadapkan pada persoalan yang sangat bertolak belakang dengan kemauannya. Apa yang dikhawatirkannya akhirnya tiba juga, Kartini dilamar untuk selanjutnya berstatus menjadi Raden Ayu. Apa yang telah dipahami selama ini menjadi Raden Ayu menurut Kartini sangat tidak diinginkannya.

Kartini mengamati kehidupan perempuan yang menjadi Raden Ayu, bukan sesuatu yang membanggakan pada saat itu, karena menurutnya perkawinan bagi perempuan menurut adat yang berlaku ketika itu sangatlah menyedihkan. Sesungguhnya Kartini sendiri pun tidak dapat menerima ketentuan adat yang tidak adil terhadap perempuan. Dari suratnya juga dapat dipahami sesungguhnya Kartini sangat anti terhadap poligami dan perihatin terhadap perempuan pribumi yang sudah dikawinkan pada usia yang sangat muda (Rosyadi, 2010 : 118-119). Kartini hanya dapat meratapi nasib, selain disebabkan karena tradisi yang masing sangat kolot juga karena kondisi keluarga yang tidak semua bersimpati dengan gagasan-gagasannya. Kartini mengambil keputusan yang demikian berat, tetapi semua berdasarkan atas pertimbangan agar orang sekitarnya tidak merasa kecewa dengan keputusan untuk belajar ke luar negeri, terutama ayahnya yang tergolong berpikiran maju juga tidak dapat berbuat banyak menghadapi tradisi adat yang berlaku pada saat itu. Seperti yang ditulis Kartini dalam suratnya kepada Stella Zeehandelaar, berikut :

“...ayahku tidak pernah mengira, bahwa kesempatan yang diberikan kepada anakanakgadisnya telah menimbulkan keinginankeinginan dalam diriku yang bertentangan dengan apa yang ditentukan oleh adatistiadat Jawa bagi gadis-gadis seperti aku...." (Soebadio dan Saparinah Sadli, 1990 : 4647).

Jika diamati, bahwa perjuangan Kartini untuk menentang adat perkawinan melalui perjodohan dan sistem poligami secara berlahan dapat diredam. Semua ini dilakukan selain Ia sendiri tidak sanggup untuk menentangnya juga kerena demi menjaga nama baik keluarga terutama ayahnya di lingkungan masyarakat adatnya.Namun dibalik semua masalah yang dihadap Kartini antara belajar ke negeri Belanda atau menerima lamaran perkawinan dengan laki-laki yang sudah beristri ? Kartini akhirnya sadar tidak mungkin memaksakan kehendaknya, tetapi di balik semua ini Kartini tetap berharapan perjuangannya akan berlanjut walaupun dalam suasana yang berbeda. Kebetulan calon suaminya selain sebagai Bupati, juga berpikiran maju dan memberikan dukungan bagi Kartini untuk melanjutkan cita-citanya dalam memberikan pendidikan baik untuk anakanak dari suaminya maupun para orang tua yang akan menyekolahkan anak-anak mereka. Dalam hal itu suami Kartini sudah memikirkan untuk mendirikan sekolah. Dalam suratnya, antara lain Kartini menggambarkan suaminya juga memiliki 
gagasan dan pemikiran yang sejiwa dengan citacita Kartini, berikut :

“...sebagai istri seorang pria yang agung pendiriannya, yang membawa saya dalam melaksanaan cita-citaku..Sekarang semua itu bagi saya menjadi sarana untuk lebih cepat mencapai tujuanku..Rencana kami mengenai pendidikan dan pengajaran berjalan terus meskipun saya sudah kawin.. Sekolah kami di Japara diteruskan oleh adik-adik saya..Disini saya juga sudah mulai. Putri-putriku sendiri yang menjadi muridku pertama...." (Soeroto, $1983: 379$ ).

Di sisi lain, bahwa kenyataannya Kartini merasa terpaksa memilih untuk dikawinkan dengan seorang laki-laki yang juga sudah mempunyai istri. Kartini sudah sering mengamati tentang posisi perempuan yang hidup berpoligami, terutama tentang Ibunya sendiri yang menjadi istri kedua. Dalam suratnya, Kartini menulis kapada Rosa Abendanon tentang nasib ibu kandungnya, bahwa Ia telah melihat neraka dari dekat (Rosyadi, 2010 : 44). Namun Kartini cukup cerdas dalam mengantisipasi posisi yang akan dihadapi dalam perkawinannya. Dapat dimaklumi bahwa Katini bersedia kawin karena tidak ada pilihan lain, namun Ia tetap pada pendiriannya untuk tetap dapat melanjutkan cita-cita mencerdaskan dan meningkatkan tarap hidup perempuan setara dengan laki-laki termasuk dalam perkawinan. Berbeda dengan sekarang kondisi sudah berubah, masa pingit, kawin paksa sudah semakin jarang bahkan semakin musnah. Akan tetapi model pendekatan Kartini untuk memperjuangkan kesetaraan gender dalam perkawinan tetap penting dijadikan inspirasi bagi kaum feminis dewasa ini.

\section{Model Pendekatan dalam Membina Kesejahteraan Rakyat Kecil}

Melalui surat-surat Kartini dapat diketahui dan dipahami, bahwa Kartini tidak saja memiliki gegasan cemerlang untuk kemajuan bangsanya, laki-laki maupun perempuan, tidak hanya terbatas pada keinginannya untuk memperbaiki kedudukan perempuan dalam perkawinan, namun Kartini juga mempunyai jiwa seni yang tinggi dan merasa bangga terhadap seni budaya bangsanya. Sejarah mencatat, Kartini memiliki daya seni yang tinggi. Hal ini dapat dilihat dari salah satu hasil karya seni membatik dan melukis, pernah dipamerkan di Den Haag tahun 1898 dan dikunjungi oleh Ratu Wilhelmina. Seni membatik dan seni lukisan Kartini oleh para sarjana dinilai sudah mempunyai nilai dan bermutu sebagai karya orang terpelajar (Sudjoko, 1983).

Selama masa pingitan, Kartini seakan tidak berhenti untuk mengenyam pengetahuan melalui bahan bacaan yang tersedia di Kabupaten. Seakan jiwa kreatifnya tidak pernah Ia hentikan. Selain itu bersama saudara perempuannya, Kartini pun menekuti bakatnya untuk membatik dan melukis. Koleksi batik Kartini disebut sebagai yang paling menarik perhatian. Koleksi pembatikan itu disertai dengan tulisan sebagai penjelasan dan disusun dengan bahasa Belanda. Dengan tulisan yang dirangkai dengan baik, sehingga pembatikan mulai dari bahan mentah hingga menjadi kain batik dapat diketahui oleh para pengunjung pameran. Bahkan semua kain batik dan alat-alat pembatikan dijadikan bagian penting dalam bab pertama dari buku standard De Batikkunst in Ned.Indie en haar Geschiedenis (Kesenian Batik di Hindia Belanda dan Sejarahnya) oleh G.P. Rouffaer dan Dr.H.H.Juynboll (Soeroto, 1983 : 101).

Selepas masa pingitan berkat ayahnya, Kartini dapat mengenal kehidupan rakyat dari dekat. Selain prihatin melihat penderitaan rakyat di desa-desa yang pernah Ia kunjungi bersama ayahnya juga tumbuh rasa kedekatan dan perhatian yang besar untuk dapat meningkatkan kesejahteraan rakyat. Kartini juga sempat mengamati dan merasa kagum terhadap daya seni yang dimiliki oleh rakyat Japara khususnya dalam seni ukir. Kemudian muncul ide atau gagasan Kartini untuk dapat memberikan pembinaan dan memperkenalkan hasil karya rakyat kepada masyarakat yang lebih luas.

Salah satu cara untuk memperkenalkan hasil karya seni rakyatnya, Kartini berusaha menyampaikan melalui surat (1 Agustus 1901) 
kepada Ny.Abendanon ( Sutrisno, 2000 : 97) pada bagian suratnya ditulis sebagai berikut :

“...,seniman pengukir, sebutan yang Nyonya berikan kepadanya, telah menghasilkan sesuatu yang bagus lagi. Sebuah kotak lengkap dengan ukiran cerita wayang...,juga buatan Bumiputra...."

Surat tersebut di atas menunjukkan betapa bangganya Kartini memperkenalkan hasil karya Bumiputra. Disini tampak model pendekatan Kartini bukan mementingkan bakat seni yang dimiliki saja, namun juga untuk kepentingan para pengrajin seni ukir yang menurutnya perlu mendapat pembinaan untuk dapat meningkatkan kesejahteraan hidup mereka. Bagaimana pula yang dapat dilakukan Kartini agar mendapatkan modal untuk para pengrajin seni ukir. Salah satu cara agar para pengrajin seni ukir tetap dapat berkarya memenuhi pesanan para konsumen, dapat dilihat pada bagian suratnya kepada Ny. Abendanon (101-1902) yang diterjemahkan oleh Sulastin Sutrisno (2000), sebagai berikut :

“...seniman-seniman kami yang pandai-pandai tidak memiliki modal kerja sehingga antara lain tidak mungkin bagi mereka mempunyai persediaan ukiran kayu. Setiap orang yang datang ke sini hendak membeli barang ini atau itu, tetapi harus selalu pergi lagi dengan kecewa...Karena itu saya senang sekali bahwa Nyonya mengirimkan uang lebih dulu kalau Nyonya memesan ini atau itu. Dari uang itu saya beri dulu sebagian dari yang harus diterimanya untuk membeli kayu dan membayar upah dan kenek-keneknya....”

Karajinan lain juga mendapat perhatian Kartini. Japara selain dikenal dengan seni ukir kayu juga pertukangan emas dan tekstil. Untuk pertukangan ini Kartini bersama saudara perempuannya berniat untuk memperkenalkan dan mengembangkannya, seperti yang ditulis Kartini pada salah satu suratnya, berikut :
“...Saya sudah bicara dengan tukang emasnya supaya pergi ke Solo untuk belajar membuat barang-barang dari kulit penyu. Orangnya langsung menyetujuinya. Sekarang ia sudah dapat membuat sisir, karena sudah mempunyai alat-alatnya, tetapi belum dapat mengkilatkannya. Itu akan dipelajarinya di Solo. Di sana iajuga akan belajar mengerjakan bahan tanduk dan kulit mutiara. Kami baru pada taraf paling permulaan untuk meningkatkan kembali kesenian kami yang indah ini, dan sudah tentu semua itu dapat segera sempurna....”

Di dalam suratnya yang lain Kartini menulis tentang perasaan kagum dan mempunyai harapan terhadap karya seni rakyat pribumi, antara lain sebagai berikut :

“...Alangkah senangnya hati kita melihat pertukangan yang saya sebut tadi benarbenar mulai hidup...Dan ada pula anak-anak yang minta diajar menjadi tukang ukir kayu. Ada suatu hal yang lebih menggirangkan hati saya, ialah diantara anak-anak tangan itu ada anak kota jadi bukanlah anak dari Belakang Gunung, dusun tukang-tukang ukir kayu itu...Pekerjaan kami akan diteruskan oleh adik-adik kami,kalau kami tiada lagi di sini; selama masih perlu diberi pimpinan, akan kami pimpin dia dari jauh...." ( Pane, 2000 :173).

\section{SIMPULAN}

Dari latar belakang masalah di atas dapat ditarik beberapa simpulan :

1. Melalui surat-surat Kartini dapat dipahami perjuangan emansipasi dalam pendidikan bukan hanya semata-mata untuk perempuan jawa, namun juga untuk kemajuan bangsanya, yaitu baik perempuan ataupun laki-laki. Dalam perjuangan emansipasinya Kartini sangat menghormati dan berusaha untuk mendapatkan dukungan dan simpati kaum laki-laki. Kartini berseru agar lakilaki dan perempuan seharusnya bersatu 
dan bersama-sama dalam mengentaskan pendidikan.

2. Melalui surat-suratnya Kartini sangat menentang terjadinya perkawinan perempuan dalam usia yang masih sangat muda,sertaantidengan perkawinan poligami. Keadaan menyebabkan Kartini Kartini tidak dapat menghindari untuk perkawinannya dengan laki-laki yang sudah beristri pula. Model pendekatan Kartini dalam mengambil keputusan dengan terpaksa memilih untuk dikawinkan dibandingkan meneruskan pendidikan ke luar negeri. Hal ini dilakukan agar tidak menimbulkan konflik. Namun Kartini dengan penuh keyakinan, bahwa dalam perkawinan akan lebih banyak dapat diperbuat untuk cita-citanya. Model pendekatan Kartini dilakukan secara fungsional, karena untuk cita-citanya Kartini selalu berharap kemajuan pendidikan untuk perempuan dan bangsanya, baik laki-laki maupun perempuan.

3. Kartini selain dikenal sebagai pejuang emansipasi perempuan Indonesia, sebagai perintis pergerakan nasional Iandonesia, Kartini juga dikenal memiliki daya seni yang tinggi dalam seni membatik dan seni lukis, juga sangat peduli terhadap seni budaya rakyat Japara. Kepedulian terhadap seni budaya rakyat Bumiputra dibuktikannya dengan berusaha memberikan pembinaan terhadap para seniman agar hasil karyanya tidak saja terkenal, tetapi juga mampu meningkatkan kesejahteraan rakyatnya.

Model pendekatan yang dilakukan oleh Kartini kiranya masih relevan dengan ide dan gagasangagasan generasi penerus bangsa pada saat ini dalam mewujudkan cita-cita kesetaraan gender, baik dalam bidang pendidikan, maupun dalam berkarya tanpa menimbulkan konflik dimana pendidikan dan berkarya hanya untuk kaum lakilaki. Model pendekatan fungsional seharusnya dilakukan, baik laki-laki maupun perempuan mendapat perlakuan setara dan adil dalam pendidikan, perkawinan, maupun berkarya sesuai dengan konteks kemampuan masing-masing individu.

\section{DAFTAR PUSTAKA}

Fakih, Mansour. 1999. Analisis Gender \& Tranformasi Sosial. Yogyakarta : Pustaka Pelajar Offset.

Megawangi, 1999. Membiarkan Berbeda Sudut Pandang Baru tentang Relasi Gender. Bandung : Mizan.

Moedjanto, G. 1983.Kartini tentang Politik Kebangsaan. Jakarta : Kompas.

Pane, Armyn. 2000. Habis Gelap Terbitlah Terang. Jakarta : Balai Pustaka.

Rosyadi, Imron. 2010. R.A.Kartini Biografi Singkat 1879-1904. Jogjakarta : Garasi House Of Book.

Soebadio, Haryati dan Saparinah Sadli. 1990. Kartini Pribadi Mandiri. Jakrta : PT Gramedia Pustaka Utama.

Soeratman,KI. 1990.Kartini Dan Pendidikan, dalam Satu Abad Kartini 1879-1979. Jakarta : Pustaka Sinar Harapan.

Soeroto, Sitisoemandari. 1983. Kartini Sebuah Biografi. Jakarta : Gunung Agung.

Sudjoko. 1983. "Kagunan” Bagi Kartini. Jakarta : Kompas

Sutrisno,Sulastin.200o. Kartini Surat-surat kepada Ny.R.M.Abendanon-Mandri dan Suaminya. Jakarta : Jambatan. 